\title{
LEGUMINOSAS E SEUS EFEITOS SOBRE PROPRIEDADES FÍSICAS DO SOLO E PRODUTIVIDADE DO MAMOEIRO 'TAINUNG 1'
}

\author{
JOSÉ EDUARDO BORGES DE CARVALHO 2 , LUCY COELHO LOPES ${ }^{3}$, ANA MARIA DE AMORIM ARAÚJO 4 , LUCIANO \\ DA SILVA SOUZA ${ }^{2}$, RANULFO CORRÊA CALDAS ${ }^{2}$, CARLOS ALBERTO DALTRO JUNIOR ${ }^{5}$, LÍCIA LEMOS DE \\ CARVALHO $^{5}$, ANTONIO ALBERTO ROCHA OLIVEIRA ${ }^{2}$, ROSANE CARDOSO DOS SANTOS ${ }^{5}$
}

\begin{abstract}
RESUMO - Conduziu-se um experimento no período de junho 1998 a dezembro de 2000 na Escola de Agronomia da Universidade Federal da Bahia, em Cruz das Almas, em um Latossolo Amarelo álico coeso para avaliar o impacto do manejo de práticas melhoradoras sobre as propriedades físicas desses solos e a produtividade do mamoeiro. Os tratamentos foram: 1- capina em área total; 2-grade nas entrelinhas e herbicida nas linhas de plantio; 3- capina em área total + subsolagem; 4- subsolagem + feijão-de-porco (Canavalia ensiformis) nas ruas da cultura; 5- Subsolagem + crotalária (Crotalaria juncea) nas ruas da cultura; 6- subsolagem + caupi (Vigna uguiculata) nas ruas da cultura; 7- subsolagem + calagem + gesso agrícola e feijão-deporco nas ruas da cultura; 8- subsolagem + vegetação nativa nas ruas da cultura, roçada quando necessária. O delineamento experimental foi em blocos casualizados, com três repetições. Cada parcela foi composta por 36 plantas das quais 16 úteis, em espaçamento de $3 \times 2 \mathrm{~m}$. A subsolagem foi realizada de forma cruzada antes do plantio nos tratamentos correspondentes. As leguminosas foram plantadas em maio/junho e roçadas em setembro/outubro. O controle do mato nas linhas foi mecânico (T1 e T3) e químico com glifosato na dose de $1 \%$ v/v nos demais. Os tratamentos manejados nas entrelinhas da cultura do mamão com leguminosas proporcionaram as maiores alterações nas propriedades físicas de um Latossolo Amarelo álico coeso. Os tratamentos manejados com leguminosas e vegetação espontânea foram os que mais se evidenciaram em produtividade, expressada pelo peso total de frutos (PTF), em toneladas por hectare, e em número total de frutos por hectare NTF).
\end{abstract}

Termos de indexação: Carica papaya L., Manejo do solo, subsolagem, adubos verdes.

\section{LEGUMINOUS PLANTS AND THEIR EFFECTS ON SOIL PHYSICAL PROPERTIES AND PRODUCTIVITY OF PAPAYA 'TAINUNG 1'}

\begin{abstract}
An experiment was carried out at the Agronomy School of Federal University of Bahia, Brazil, Cruz das Almas, during the period of June 1998 to December 2000, with the objective of evaluating the impact of good management practices on soil physical properties of an alic and cohesive yellow Latosol and the productivity of papaya. The treatments were: 1 . manual weeding with hoe in total area; 2 . harrowing in the interrows and herbicide in the rows; 3 . manual weeding with hoe in total area + subsoiling ; 4 . subsoiling + jack bean (Canavalia ensiformis) in the rows; 5 . subsoiling + Crotalaria juncea in the rows; 6 . subsoiling + cowpea (Vigna unguiculata) in the rows; 7 . subsoiling + liming + gipsum and jack bean in the rows; 8 . subsoiling + spontaneous vegetation in the rows, cutting when necessary. The statistical design was randomized blocks with three replications. Experimental plots contained 36 plants, of which 16 useful, in spacing 3 x $2 \mathrm{~m}$. The treatments with subsoiling was performed in the experimental area in a crossed way before the planting. Leguminous plants were sowed in May/June and mowed in September/October. The weed control in rows was mechanical (T1 and T3) and chemical with glyphosate at dosages of $1 \%(\mathrm{v} / \mathrm{v})$ in the other treatments. The treatments with management of leguminous plants in the papaya interrows provided the greatest benefits in the soil physical properties. Treatments with leguminous plants and spontaneous vegetation produced significantly higher fruit yields, expressed in total fruit weight (ton per hectare) and showed the highest number of fruit per hectare.
\end{abstract}

Index terms: Carica papaya, Soil management, subsoiling, green manure.

\section{INTRODUÇÃO}

O mamão (Carica papaya L.) é cultivado na quase totalidade do território nacional, merecendo destaque os Estados da Bahia, Espírito Santo e Pará, cujas participações na produção nacional são, respectivamente, 56,9\%, 30,8\% e 3, $9 \%$ (IBGE, 2000). Nos Estados da Bahia e Espírito Santo, o mamoeiro é largamente cultivado na faixa dos tabuleiros costeiros, apresentando grande diversidade de solos, com predomínio do Latossolo Amarelo álico coeso, profundo, ácido, distrófico, baixa CTC e capacidade de retenção de água com pouca diferença morfológica entre horizontes.

O horizonte ou camada do solo compactado ou adensado retém o fluxo de água, permanecendo encharcado por algum tempo no período chuvoso, provocando amarelecimento e queda prematura das folhas, redução da produção ou até mesmo morte das plantas (Manica, 1982).

A acentuada sensibilidade da cultura do mamão e a competição por água pelas plantas infestantes, tem induzido aos produtores adotarem um manejo na superfície do solo para controle mecânico dessas plantas, aumentando a compactação dos solos de tabuleiros costeiros além dos cortes sucessivos do sistema radicular.
O adensamento e a compactação que ocorrem nos solos de tabuleiro, levam à busca de sistemas de manejos de solo diferenciados dos usualmente empregados pela maioria dos produtores, a fim de propiciar melhores condições para o crescimento e a produtividade das culturas neles cultivadas (Souza, 1996).

Num estudo dos efeitos da subsolagem sobre a estrutura de solos do Tabuleiro Costeiro, Santos (1992) concluiu que houve diminuição da densidade e aumento da porosidade total, macroporosidade e índice de aeração do solo nos sulcos de subsolagem, porém o mesmo não ocorreu nos entressulcos. A subsolagem e a correção da acidez do solo são práticas agrícolas que devem ser consideradas quando se estuda o manejo de um Latossolo Amarelo álico coeso (Rocha et al., 1995).

O objetivo desse trabalho foi avaliar práticas melhoradoras do solo, comparando-as aos sistemas utilizados pelos produtores, assim como sua influência na produtividade do mamoeiro 'Tainung 1'.

\section{MATERIALE MÉTODOS}

O experimento foi conduzido no período de junho de 1998 a dezembro de 2000, na Estação Experimental Potileno na Escola de

\footnotetext{
${ }_{1}$ (Trabalho 095/2003). Recebido: 10/07/2003. Aceito para publicação: 26/05/2004. Apresentado no XVII Congresso Brasileiro de Fruticultura

${ }^{2}$ Pesquisador - Embrapa Mandioca e Fruticultura, Caixa Postal 007, Cruz das Almas-BA, E-mail: jeduardo@cnpmf.embrapa.br; lsouza@cnpmf.embrapa.br; rcaldas@cnpmf.embrapa.br; alberto@cnpmf.embrapa.br

${ }^{3}$ Bolsista DTI - CNPq, Cruz das Almas - BA, E-mail lucylopes74@hotmail.com

${ }^{4}$ Bolsista CAPES e Pós-Graduanda da EAUFBA, Cruz das Almas-BA.

${ }^{5}$ Bolsista CNPq/PIBIC Embrapa Mandioca e Fruticultura.
} 
Agronomia da Universidade Federal da Bahia, no município de Cruz das Almas-BA, em solo de tabuleiro, representado pelo Latossolo Amarelo álico coeso. O delineamento experimental foi em blocos casualizados, com três repetições e oito tratamentos.

\section{Descrição dos tratamentos}

1- Capina em área total;

2- Grade nas entrelinhas e herbicida nas linhas de plantio;

3- Capina em área total + subsolagem;

4- Subsolagem + feijão-de-porco (Canavalia ensiformis) nas ruas da cultura;

5- Subsolagem + crotalária (Crotalaria juncea) nas ruas da cultura;

6- Subsolagem + caupi (Vigna uguiculata) nas ruas da cultura;

7- Subsolagem + calagem + gesso agrícola e feijão-de-porco nas ruas da cultura;

8- Subsolagem + vegetação nativa nas ruas da cultura, roçada quando necessário.

Cada parcela foi composta por 36 plantas das quais 16 úteis, no espaçamento de $3 \times 2 \mathrm{~m}$. Foi utilizada a cultivar de mamão 'Tainung 1'. A subsolagem foi realizada de forma cruzada na área experimental antes da implantação do experimento, numa profundidade média de $55 \mathrm{~cm}$, utilizando-se de um subsolador DMB, com duas hastes espaçadas a $1,5 \mathrm{~m}$. A adubação comum a todas as parcelas foi realizada com NPK conforme análise química do solo, seguindo a recomendação de Luna (1989). Quanto à calagem, utilizou-se calcário dolomítico aplicado a lanço. Apenas no tratamento 7 foi usada a mistura de $2 / 3$ de calcário e $1 / 3$ de gesso agrícola.

O feijão-de-porco, Crotalaria juncea e feijão caupi, foram plantados nas entrelinhas do mamoeiro em sistema de plantio direto, no período das águas (maio/junho de 1999 e 2000), utilizando-se de $80 \mathrm{~kg}$; $25 \mathrm{~kg} ; 40 \mathrm{~kg}$ de semente por hectare, respectivamente. Foram roçadas no final desse período (setembro/outubro), a uma altura média de $20-25 \mathrm{~cm}$ do solo, com roçadeira acoplada ao trator. As plantas infestantes foram controladas em área total com capinas mecânicas (T1 e T3). Nos demais tratamentos, foi feita capina química com glifosate nas linhas da cultura. Nas entrelinhas, o controle mecânico com grade no tratamento 2 e com roçadeira no tratamento 9. Para os tratamentos 4 a 8 , manejados com leguminosas, houve uma aplicação de glifosato para controle das plantas daninhas e posterior plantio direto dos adubos verdes.

Para as avaliações físico - hídricas do solo, as amostras foram coletadas na área experimental, aos dezoito meses após aplicação dos manejos. Em cada tratamento e repetição, foi aberta uma trincheira de 50 x 50 x $50 \mathrm{~cm}$, coletando-se amostras indeformadas nas profundidades de 0-10; 10-20; 20-30; 30-40 cm, utilizando-se de anéis volumétricos de 312,31 $\mathrm{cm}^{3}$ para a determinação da porosidade total, macro e microporosidade e densidade do solo, e cilíndro de $51,38 \mathrm{~cm}^{3}$, para a determinação da retenção de umidade. As análises foram realizadas no Laboratório de Física do Solo da Embrapa Mandioca e Fruticultura, seguindo metodologia da Embrapa (1979). A condutividade hidráulica saturada foi determinada em laboratório, em permeâmetro de carga constante, usando amostras com estrutura indeformada coletadas em anéis volumétricos. O cálculo foi efetuado com base na equação de Darcy (Embrapa, 1979).

As variáveis número e peso total de frutos foram obtidas pela contagem e pesagem cumulativa das colheitas efetuadas nas 16 plantas úteis de cada parcela, no período de 18 meses.

\section{RESULTADOSE DISCUSSÃO}

Não se observaram grandes variações nas características químicas do solo, exceção feita para a redução no teor de potássio e para o aumento no teor de matéria orgânica nos três grupos de manejos testados, descartando-se algum efeito dos tratamentos para os resultados obtidos (Tabela 1).

Pelos resultados apresentados na Figura 1A, não se observou diferença estatística significativa entre os tratamentos, para porosidade total, na profundidade de 0 a $0,40 \mathrm{~m}$, pelo teste de Tukey, a $\mathrm{P}<5 \%$, discordando dos resultados obtidos por Santos (1992) e Nacif (1994), que observaram aumento da porosidade total e conseqüente redução da microporosidade com uso de subsolagem.

Com relação à macroporosidade, apenas o tratamento 6 (subsolagem + caupi nas entrelinhas da cultura) diferiu $\mathrm{P}<5 \%$ do tratamento 2 (grade nas entrelinhas e herbicida nas linhas) e do tratamento 8 (subsolagem + vegetação espontânea nas entrelinhas roçada quando necessário) sem, contudo, diferir significativamente dos demais tratamentos. Esses resultados estão coerentes com os de Santos (1992), Nacif (1994) e em pomares cítricos, por Carvalho et al. (1998, 1999 e 2001). Admite-se o comportamento do tratamento 8 , onde não foram observadas alterações expressivas na macroporosidade, à importância de associar a subsolagem no preparo inicial do solo, ao manejo nas entrelinhas do mamoeiro, de leguminosas com sistema radicular vigoroso, para a melhoria da estrutura dos solos de Tabuleiros Costeiros, uma vez que a adoção dessas práticas, separadamente, não contribui para minimizar, substancialmente, o adensamento desses solos e os efeitos negativos do trânsito de máquinas sobre a compactação. Quanto ao comportamento discrepante do tratamento 4 em relação aos demais tratamentos com leguminosas, não se encontrou uma explicação técnica. $\mathrm{O}$ resultado obtido no tratamento 2 foi atribuído ao manejo adotado, com ausência da subsolagem e uso intensivo de grade para o controle de plantas daninhas nas entrelinhas, contribuindo para aumentar a compactação subsuperficial, com redução da macroporosidade (Figura 1B).

Para microporosidade (Figura 1C), apenas o tratamento 3 (capina em área total + subsolagem), diferiu p $<5 \%$ dos tratamentos $1 ; 6$ e 7 . Não se atribui esse resultado ao efeito do tratamento, haja vista não haver apresentado para porosidade total, macroporosidade e densidade do solo, alguma diferença estatisticamente significativa para os demais tratamentos por Tukey, a 5\% (Figura 1). Para os demais tratamentos, não se observou algum efeito significativo sobre essa característica física do solo.

Os tratamentos testados não diferiram $\mathrm{P}<5 \%$ entre si, para reduzir a densidade do solo (Figura 1D). Essas altas densidades foram, também, encontradas em solos de tabuleiros por Souto Maior (1996), Dantas et al. (1998) e Santos (1998). Apesar de os tratamentos não diferirem estatisticamente, chama-se a atenção para os valores observados nos tratamentos 6; 7 e 5, com 1,51 kg.dm ${ }^{-3}, 1,53 \mathrm{~kg} \cdot \mathrm{dm}^{-3} \mathrm{e} 1,54 \mathrm{~kg} \cdot \mathrm{dm}^{-3}$, onde a subsolagem antes do plantio, associada ao manejo de leguminosas melhoradoras de solo, poderá contribuir, ao longo dos anos, para reduzir a densidade desses solos. Nos tratamentos vegetação espontânea (T8) e capina em área total (T3), subsolados, mas sem plantio de leguminosas

TABELA 1 - Resultados das análises químicas do solo, na profundidade média de 0-40 cm, antes da aplicação dos tratamentos e no final do trabalho. Cruz das Almas-BA, 1998 e 2000.

\begin{tabular}{|c|c|c|c|c|c|c|c|c|c|c|c|c|c|}
\hline TRATAMENTOS & $\begin{array}{c}\mathrm{pH} \\
\mathrm{H}_{2} \mathrm{O}\end{array}$ & $\begin{array}{c}\mathrm{P} \\
\mathrm{mg} / \mathrm{dm}^{3}\end{array}$ & $\mathrm{~K}$ & $\mathrm{Ca}$ & $\mathrm{Mg}$ & $\begin{array}{c}\mathrm{Ca}+ \\
\mathrm{Mg}\end{array}$ & $\mathrm{Al}$ & $\begin{array}{c}\mathrm{Na} \\
\mathrm{cmolc} / \mathrm{dm}^{3}\end{array}$ & $\mathrm{H}+\mathrm{Al}$ & $\mathrm{S}$ & CTC & $\begin{array}{l}\mathrm{V} \\
\%\end{array}$ & $\begin{array}{l}\text { M.O } \\
\text { g/kg }\end{array}$ \\
\hline \multicolumn{14}{|c|}{ ANÁLISE QUİMICA INICIAL } \\
\hline \multicolumn{14}{|c|}{ ANÁLISE QUÍMICA FINAL } \\
\hline Coberturas T4 a T7 & 4,6 & 3,3 & 0,1 & 1,1 & 0,7 & 1,8 & 0,4 & 0,1 & 3,1 & 2,0 & 5,0 & 39,1 & 6,5 \\
\hline Espontâneas T8 & 4,6 & 4,2 & 0,1 & 1,2 & 0,7 & 1,8 & 0,4 & 0,1 & 3,3 & 2 & 5,3 & 38,6 & 7,5 \\
\hline
\end{tabular}



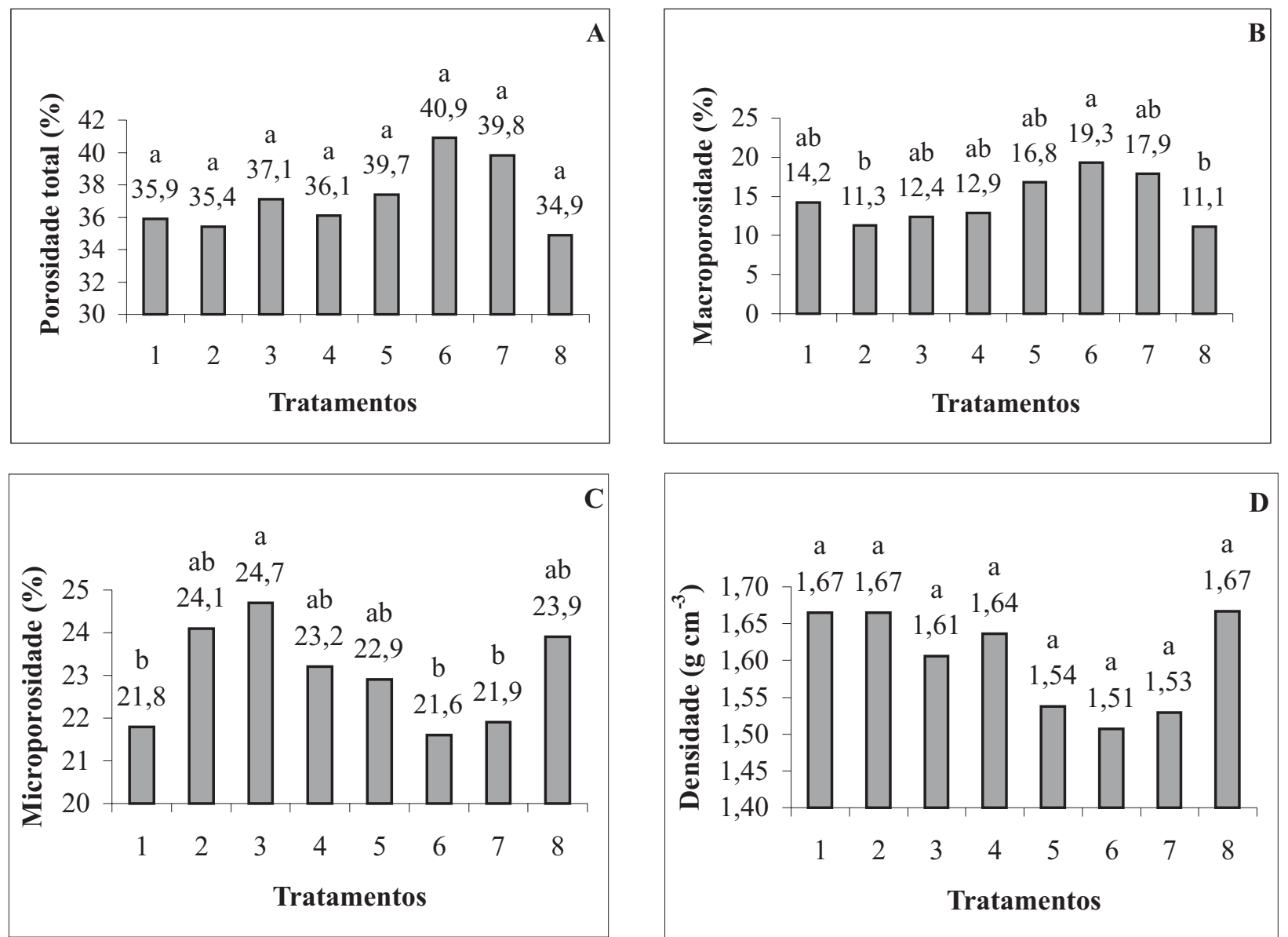

FIGURA 1 - Porosidade total (A), macroporosidade (B), microporosidade (C) e densidade do solo (D), na profundidade de 0-40cm, dezoito meses após iniciado o trabalho. Comparação de médias por Tukey, a 5\% (Cruz das Almas-BA, 2000).

com sistema radicular profundo e vigoroso, observaram-se valores elevados para a densidade do solo e próximos aos verificados nos tratamentos com capina em área total (T1) e grade nas entrelinhas e herbicidas nas linhas (T2), não subsolados, confirmando que o plantio de leguminosas é um dos requisitos necessários para o sucesso da subsolagem mecânica (Sanches, 1998).

Para condutividade hidráulica saturada, o tratamento 7 (subsolagem + feijão-de-porco com calcário agrícola) diferiu significativamente $\mathrm{P}<5 \%$ dos tratamentos $1 ; 2 ; 3 ; 4$ e 8 sem, contudo, diferir dos tratamentos 5 e 6 . Os tratamento 2 e 8 diferiram dos tratamentos 6 e 7, mas não diferiram entre si e dos demais tratamentos (Figura 2A). Esses resultados levam a admitir um efeito positivo e significativo da associação subsolagem com leguminosas no manejo do solo na cultura do mamão, sobre a condutividade hidráulica saturada da água no solo.

Os dados observados nos tratamentos, sem o manejo de

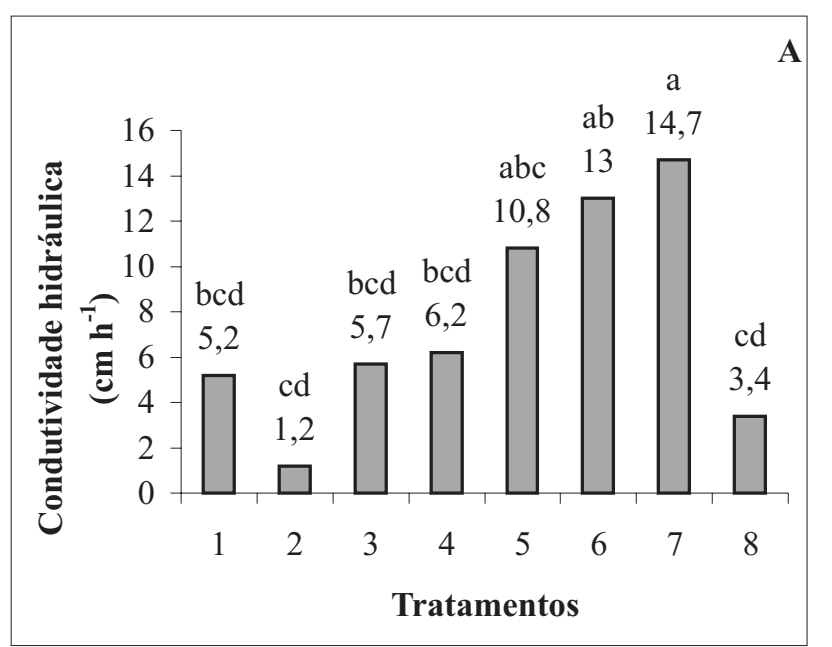

leguminosas, são atribuídos à menor macroporosidade desses tratamentos, responsável principal, segundo Hillel (1970), Reichardt (1985) e Libardi (1995), pela velocidade do fluxo de água.

As variações na disponibilidade de água, dentro de cada tratamento, são mostradas na Figura 2B. Os tratamentos não diferiram $\mathrm{P}<5 \%$ entre si. Destacam-se os percentuais observados nos tratamentos 5; 6 e 7 e coerentes com aqueles apresentados por Taylor e Beltrame (1980) e Cassel (1979). Exceção feita à baixa disponibilidade encontrada no tratamento 4, não atribuído ao efeito do tratamento, admitindo-se a algum fator no solo por ocasião da amostragem, haja vista que a condutividade hidráulica é, das propriedades físicas do solo, a que apresenta maior variabilidade.

A produção expressa pelo peso total de frutos (PTF), em toneladas por hectare e número total de frutos (NTF) por hectare, em dezoito meses de colheita para a variedade 'Tainung 1', encontra-se na

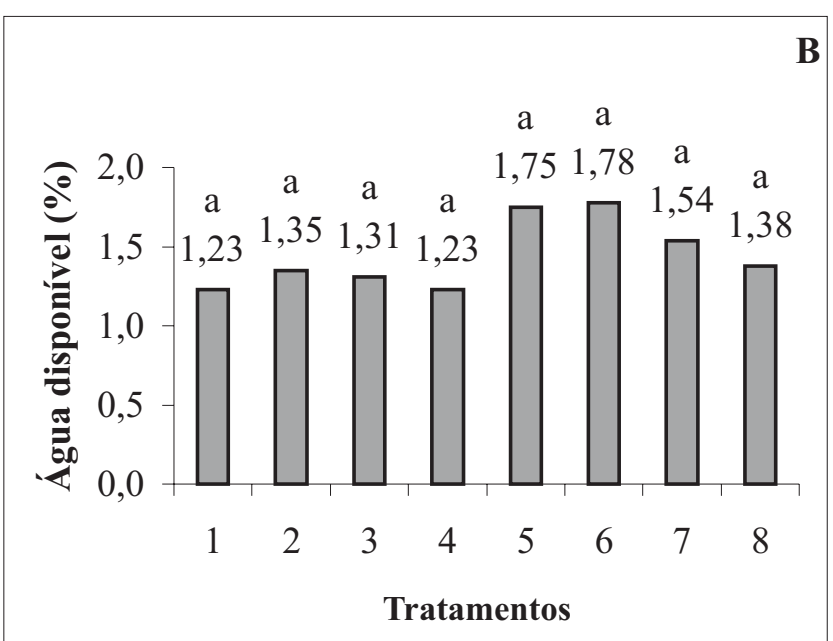

FIGURA 2 - Condutividade hidráulica saturada (A) e água disponível (B), na profundidade de 0-40cm, dezoito meses após iniciado o trabalho. Comparação de médias por Tukey, a 5\% (Cruz das Almas-BA, 2000). 

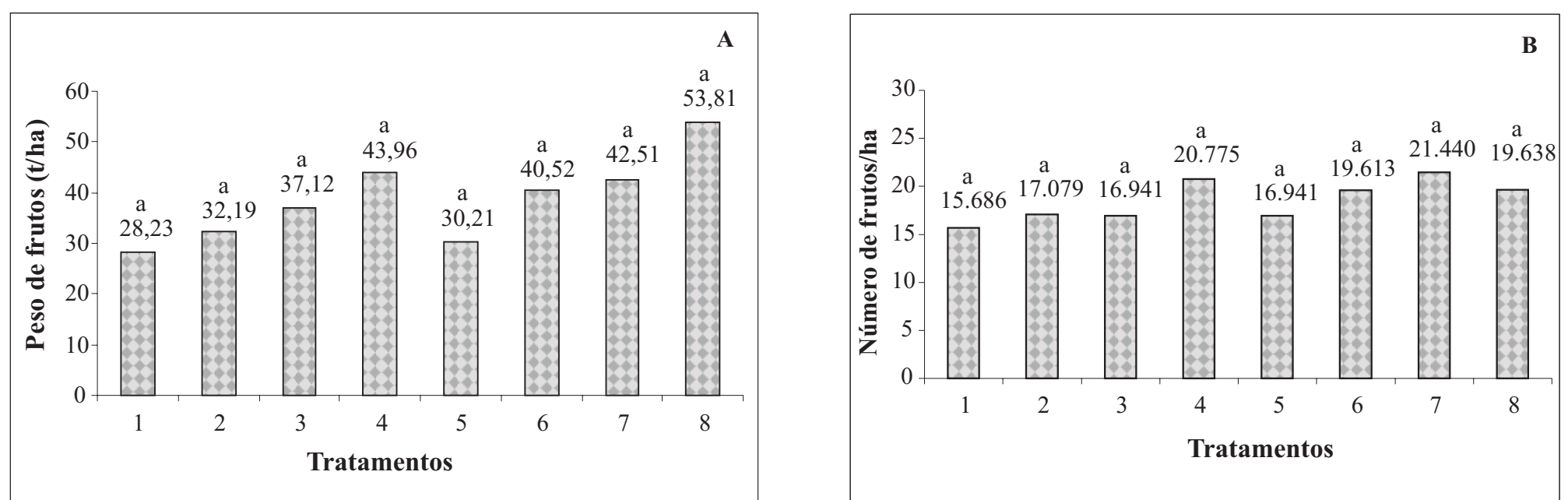

FIGURA 3. Peso total de frutos (PTF) em t/ha e número total de frutos por hectare (NTF), após 18 meses, nos diferentes tratamentos estudados. Comparação de médias por Tukey, a 5\% (Cruz das Almas-BA, 2000).

Figura 3. Apesar de não ter havido diferenças significativas entre os tratamentos pelo teste de Tukey, a 5\%, observou-se, tanto para peso como para número de frutos, que os tratamentos subsolados e manejados com coberturas vegetais (leguminosas: T4, T6 e T7) e vegetação espontânea (T8) foram os que mais se destacaram. Exceção feita ao tratamento 5 que, apesar de ter contribuído para a melhoria das propriedades físicas do solo, não apresentou uma resposta compatível de produção, não sendo assim, atribuída ao efeito de tratamento. Esses resultados vêm confirmar os já obtidos com citros por Carvalho et al. (1999), onde o manejo de coberturas vegetais + subsolagem foi fundamental no sistema de produção para o aumento de produtividade, nas condições dos solos de Tabuleiros Costeiros.

\section{CONCLUSÃO}

O uso da subsolagem no preparo do solo para o plantio, associado ao manejo de leguminosas nas entrelinhas da cultura para o controle integrado de plantas infestantes proporcionaram os maiores impactos na melhoria das propriedades físicas de um Latossolo Amarelo álico coeso, refletindo diretamente no aumento de produtividade.

\section{REFERÊNCIASBIBLIOGRÁFICAS}

CARVALHO, J.E. B. de; SOUZA, L. da S.; SOUZA, L.D.; CALDAS, R.C.; RAMOS, W. F.; COSTA NETO, A . de O .; ARAÚJO, A . M. de A .; LOPES, L. C.; SILVEIRA, J. R. da S. Manejo do solo no controle integrado de plantas daninhas em citros. Revista Brasileira de Fruticultura, Jaboticabal, v. 20, n. 1, p. 21-27, 1998.

CARVALHO, J. E. B. de; SOUZA, L. da S.; JORGE, L.A. de C.; RAMOS, W. F.; COSTANETO, A. de O .;ARAÚJO, A. M. de A.; LOPES, L.C.; JESUS, M. S. de. Manejo de coberturas do solo e sua interferência no desenvolvimento do sistema radicular da laranja "Pêra". Revista Brasileira de Fruticultura, Jaboticabal, v. 21, n. 2, p. 140 - 145, 1999.

CARVALHO, J.E.B. DE C.; JORGE, L.A. de C.; RAMOS, W.F.; ARAÚJO, A.M. DE A. Manejo de cobertura do solo e desenvolvimento do sistema radicular da combinação laranja 'Pêra'/limão 'Cravo' na Bahia e Sergipe. Laranja, Cordeirópolis, v.22, n.1, p. 259-269, 2001.

CASSEL, D.K. Subsoiling. Crops and soils magazine, Madison, v. 32, p.7$10,1979$.

DANTAS, J. A.; SANTOS, M.C.; HECK, R.J. Caracterização de podzólicos amarelos irrigados e não irrigados do submédio São Francisco. Revista Brasileira de Ciência do Solo, Viçosa, v.22, n.4, p.761-771, out./dez. 1998.

EMBRAPA. Serviço Nacional de Levantamento e Conservação de Solo. Manual de métodos de análise de solo. Rio de Janeiro: SNLCS, 1979. Não paginado.
HILLEL, D. Solo e água: fenômeno e princípios físicos. Porto Alegre: Meridional "EMMA", 1970.231p.

IBGE. Site IBGE (PAM, 1997). Disponível em: <http// www.Sidia.ibge.gov.br.>. Acesso em: 4 abril 2000.

LIBARDI, P. L. Dinâmica da água no solo. Piracicaba, 1995. 497p..

LUNA, J.V.U. Mamão (Carica papaya L.). In: COMISSÃO ESTADUAL DEFERTILIDADEDO SOLO. Manual de adubação e calagem para o Estado da Bahia. Salvador: CEPLAC/EMATERBA/EMBRAPA/ EPABA/NITROFERTIL, 1989.p. 130-131.

MANICA, I. Fruticultura tropical: mamão. São Paulo: Agr.Ceres, 1982. 255p.

NACIF, P.G.S. Efeito da subsolagem em propriedades físico - hídricas de um latossolo amareloálico coeso, representativo do Recôncavo baiano. 1994. 75f. Dissertação (Mestrado em Agronomia)- Universidade Federal de Viçosa, Viçosa, 1994.

REICHARDT, K. Processos de transferência no sistema solo-plantaatmosfera. 3.ed. Piracicaba: Fundação Cargill, 1985. 286p.

ROCHA, E. S.; REZENDE, J. de O.; PORTELA, SANTOS , S.O.; O.; COSTA, J. A. Efeito da subsolagem e da correção da acidez do solo no crescimento do sistema radicular do mamoeiro (Carica papaya) variedade improved. In: CONGRESSO BRASILEIRO DA CIÊNCIA DO SOLO, 25., 1995, Viçosa. Anais... Viçosa: SBCS / UFV, 1995. v.4, p.1446-1447.

SANCHES, A . C. Conservação do solo em pomares cítricos. In: SEMINÁRIO INTERNACIONAL DE CITROS - TRATOS CULTURAS, 5., 1998, Bebedouro. Anais... Bebedouro: Fundação Cargill, 1998. p.167-187.

SANTOS, D. M. B. Efeito da subsolagem mecânica sobre a estrutura de um solo de "tabuleiro" (Latossolo Amareloálico coeso) no Município de Cruz das Almas - Bahia (Caso 2). 1992. 87f. Dissertação (Mestrado em Geociências)-Instituto de Geociências, Universidade Federal da Bahia, Salvador, 1992.

SANTOS, E.E.F. Influência da agricultura irrigda nas propriedades de Latossolos e podzólicos da Região do submédio São Francisco. 1998. 103f. Dissertação (Mestrado em Ciência do Solo)- Universidade Federal Rural de Pernambuco, Recife, 1998.

SOUTO MAIOR, F.C. de. Podzólicos plínticos e os efeitos do cultivo de uva com irrigação no submédio São Francisco. 1996. 107f. Dissertação (Mestrado em Ciência do Solo) Universidade Federal Rural de Pernambuco, Recife, 1996.

SOUZA, L. da S. Uso e manejo dos solos dos tabuleiros costeiros. In: REUNIÃOTÉCNICASOBRE SOLOS COESOS DOS TABULEIROS COSTEIROS, 1996, Cruz das Almas. Anais... Aracaju: EMBRAPACPATC, 1996. p. 36-75.

TAYLOR, J . C. ; BELTRAME, L. F. S. Por que, quando e como utilizar a subsolagem. Lavoura Arrozeira, Porto Alegre, v. 33, n. 321, p. 34-44, maio/jun. 1980. 